\title{
O tempo presente e os sentidos dos museus de história
}

Present time and the meanings of History Museums

Cecilia Helena de Salles Oliveira*

\section{Resumo}

O propósito deste artigo é o de questionar as relações entre os museus de história e a construção de narrativas nacionais e de um passado unívoco para a nação. É o tempo presente que sustenta os fundamentos dessa escrita, repondo conteúdos e interpretações destinados a fazer ver circunstâncias pretéritas. Relativizam-se, assim, continuidades nas trajetórias dessas instituições e a compreensão de que são isentas de tensões e contradições, pois uma das chaves para $o$ entendimento dos significados contemporâneos dos museus de história está no mapeamento das rupturas institucionais que sofreram e ainda sofrem, bem como no debate e na convivência conflituosa que, desde sua origem, mantêm com outros agentes de cultura.

Palavras-chave: museu; museu de história; história; memória; tempo presente.

\begin{abstract}
The aim of the article is to question the relations between history museums, the construction of national narratives and of a univocal national past. It's the present time that purports the foundations of this writing, replacing contents and interpretations destined to make past circumstances clearer. In this way, the continuity of these institutions' trajectories and the notion that they are immune to tensions and contradictions are compromised, for one of the keys to understanding the contemporaneous meanings of history museums is the mapping of the institutional ruptures that they suffered and still do to this day, as well as in the debate and in the conflictuous coexistence that, since their inception, they keep with other cultural agents.
\end{abstract}

Keywords: museum; History museum; History; memory; present time.

\footnotetext{
* Museu Paulista da USP/Pesquisadora CNPq. psalles@usp.br
} 
Museu, lugar na cidade de Alexandria, no Egito, onde se reunia, às expensas do público, um certo número de homens de letras destacados por seus méritos, como se reuniam em Atenas as pessoas que prestaram serviços à república. O nome das musas, deusas e protetoras das belas artes estava incontestavelmente na origem do nome museu ... A palavra recebeu depois um sentido mais amplo e hoje se aplica a todos os logradouros onde estão acumuladas as coisas que têm relação imediata com as artes e as musas

L'Enciclopédie, v.10, p.893-894 ${ }^{1}$

As palavras dos enciclopedistas se referem a alguns dos fundamentos da cultura antiquária e expressam as bases dos chamados gabinetes de curiosidades dos séculos XVII e XVIII. Ali, o passado presentificado em objetos, vestígios materiais e imagéticos de variada natureza, podia ser visualizado, memorizado e transmitido. ${ }^{2}$

Os museus, tal como passaram a ser conhecidos a partir do século XIX, diferenciando-se dos gabinetes, exteriorizaram outra postura em relação ao tempo: o passado estava distante do presente e somente uma reflexão científica, presidida por procedimentos disciplinares que a legitimassem, poderia torná-lo visível e útil à ação dos homens. Foi dessa perspectiva que se ergueu a crítica aos antiquários, reduzidos a papel amadorista e diletante, o que ajudou a escamotear os nexos entre a cultura histórica que acalentavam e a nova que tomava corpo, fazendo que o passado-memória e o passado construído como história aparecessem separados e em oposição. ${ }^{3}$ Nesse sentido, como apontou Michel van Praët, ${ }^{4}$ os museus são entidades públicas marcadas, no nascedouro, por tensões e contradições internas às comunidades de sábios e cientistas. Mas, por isso mesmo, até hoje, são essenciais para o mapeamento das relações, invariavelmente controversas e movediças, entre a sociedade contemporânea, a História e suas diferentes configurações.

No caso dos museus de história, propriamente, além das questões atinentes a sua inserção nesse campo de conhecimento, o que envolve contínua redefinição do lugar que ocupam frente à historiografia e aos demais centros de produção do saber histórico - a exemplo das universidades, academias e institutos -, é necessário considerar o peso de heranças políticas e simbólicas, decorrentes de vínculos de origem que os entrelaçam à formação das naciona- 
lidades, às identidades coletivas e à simultânea emergência da história e memória nacionais.

Em razão dessas injunções, tais museus constituem tema bastante complexo, uma vez que, ao longo de sua trajetória desde o século XIX, modificaram-se e adquiriram sentidos e dimensões matizados, conforme a época, protagonizando um universo de forças políticas, compartilhado por diversos agentes que com eles estabelecem intenso debate intelectual, tornando-se, concomitantemente, sujeitos e objetos de disputas sobre o passado, suas apropriações e seus usos. ${ }^{5} \mathrm{Na}$ atualidade, são interpretados como núcleos de produção de saber e de preservação de patrimônios, ${ }^{6}$ exercendo ainda amplas responsabilidades sociais, como a difusão da cultura e de conhecimentos à sociedade em geral, e o desenvolvimento de propostas e ações de caráter pedagógico e educativo.

Desse modo, não é demais lembrar, como já o fiz em outras oportunidades, ${ }^{7}$ ponderações de Beatriz Sarlo sobre a coexistência, em um mesmo momento histórico, de diferentes 'passados', construídos por intermédio de registros e preocupações sociais diferenciadas. Desse modo, ao lado da sensação de um tempo acelerado e da vertigem gerada pela rapidez com que museificação e obsolescência estão enredados no mundo contemporâneo, a história de corte acadêmico convive com sínteses históricas que visam atender ao mercado de consumo cultural e com reconstituições pautadas primordialmente nos trabalhos da memória. Essas imbricações entre manifestações díspares e mesmo incongruentes do saber histórico atingem a disciplina da história, mas sobretudo os museus, pois estes interagem cotidianamente com públicos e demandas de múltiplas feições, sendo cobrados a projetar e a discutir 'visões' do e sobre o passado (Sarlo, 2007, p.9ss). Em seus espaços mesclam-se atitudes que vão desde a contemplação daquilo que teria existido, como se objetos e imagens contivessem em si a capacidade de reproduzir ambientes e vivências pretéritas, até a crítica indignada e quase destrutiva sobre a relevância de acervos postos à exposição, já que nem todos os segmentos e classes julgam-se ali contemplados, o que aviva as discrepâncias entre experiências, expectativas nutridas sobre os museus, e representações lá projetadas.

No entanto, as controvérsias não se restringem à reação dos variados públicos que frequentam essas instituições. Para os que trabalham nesses espaços, ou com eles mantêm vínculos permanentes, os desafios estão imbricados às 
atividades de curadoria que caracterizam sua própria razão de ser. ${ }^{8}$ Os museus não apenas estão em processo recorrente de legitimação - em função dos custos implicados na preservação e ampliação de acervos e espaços físicos - como são chamados a uma constante reflexão sobre si mesmos, uma vez que se situam numa encruzilhada em que a preservação de heranças simbólicas e materiais, recebidas desde épocas pretéritas à sua organização, convive simultaneamente com o poder (e a enorme responsabilidade) de determinar critérios para a seleção de objetos, imagens e escritos os quais, retirados do circuito voraz do consumo e da destruição, serão guindados à condição de patrimônio a ser conservado no presente e no futuro. Tensões e ambiguidades marcam aproximações e distanciamentos entre refletir sobre bens culturais acumulados e ser agente do processo de patrimonialização. Estão presentes, também, no simultâneo movimento de produzir conhecimentos inovadores, contribuindo com a historiografia e a compreensão histórica da formação da sociedade brasileira, e na busca por encontrar linguagens pertinentes para difundir esses conhecimentos no âmbito de formação social fracionada e plural, como a contemporânea. A essas questões alia-se, também, a necessária problematização dos parâmetros de construção da história nacional e o trabalho de resguardar memórias e representações, por meio das quais os sujeitos históricos se reconhecem e com os quais aprenderam a se identificar.

Nesse particular, é possível afirmar que os museus de história, e em especial o Museu Paulista, referência fundamental na concepção deste artigo, lidam essencialmente com o tempo, suas representações e a historicidade dos significados que lhes foram e estão sendo emprestados. Exerceram - tal como os museus de ciências e de história natural na delimitação desses campos de saber - papel crucial, no século XIX e nos inícios do século XX, na formação da história como disciplina e na noção do 'documento' como registro material, predominantemente escrito, daquilo que aconteceu, noção essa que ainda não foi inteiramente superada, particularmente pela literatura de divulgação.

Os "etimologistas encontram na palavra historia (grega ou latina) o mesmo étimo id, que está em eidos (forma/figura) e em Idea"; a história “é a visão-pensamento do que aconteceu" (Bosi, 1988). Esse radical comum que remete à associação entre ver e saber relaciona-se, por certo, às narrativas dos primeiros historiadores - Heródoto e Tucídides. ${ }^{9}$ Entretanto, está na base dos trabalhos de inúmeros eruditos que, durante o século XIX, debruçaram-se sobre a 
escrita da história, compreendendo que, por intermédio dos museus, com suas vitrinas e salões repletos de obras de arte e objetos, essa narrativa ganharia visibilidade e se tornaria acessível a todos (Georgel, 2005, p.118-126).

A historia, como se sabe, emerge da epopeia. Vem dela e a abandona. O mundo mudou. Os deuses deixaram de aparecer; a Musa desapareceu e ficou em silêncio; além de se ter fixado a separação entre o visível e o invisível. Passar da epopeia para a história significa, em particular, trocar a evidência da visão divina ... pela visão (a estabelecer) do historiador. Aliás, é inclusive esta última que o levará a ser reconhecido como historiador. Tal como é proposta e praticada por Heródoto, ela se apresenta como análoga à - e um substituto da - visão de que se beneficiava o aedo inspirado. Adquirida pelo investigador às próprias custas, mistura de vista e de ouvido, ela é, com efeito, forçosamente incompleta e sempre precária. Em breve, Tucídides torna ainda mais rígidas as condições de seu exercício, apostando tudo na autópsia (o fato de ver por si mesmo), a única capaz de produzir um conhecimento claro e distinto ... Quando, na sequência, a historia se torna ... cada vez mais a narrativa do que aconteceu ... a questão da evidência se desloca do ver para o fazer ver... (Hartog, 2011, p.13-14)

Ao iniciar longa e instigante reflexão sobre as evidências com as quais os historiadores têm trabalhado, Hartog sugere forte vinculação entre historiadores modernos e os procedimentos de trazer à luz aquilo que tinha permanecido invisível. Os museus certamente atuaram nessa direção, e não apenas os de história, pois também a natureza e as obras de arte davam concretude à nação e às suas especificidades, cabendo aos cientistas demonstrá-las. ${ }^{10}$ Daí a criação de formas de ordenação, classificações, nomenclaturas e arranjos visuais para a exibição de coleções e objetos exemplares.

Atualmente, a crítica dessas concepções e práticas narrativas colocou sob profundo questionamento o trabalho do historiador com suas fontes e os critérios de eleição dos documentos. ${ }^{11}$ Ao mesmo tempo, verificou-se a valorização da iconografia, da materialidade da cultura e de testemunhos orais, o que ajudou a desfazer a supremacia de registros escritos e, sobretudo, passou-se a problematizar a possibilidade de o conhecimento produzido pelo historiador permitir inteligibilidade e visibilidade ao passado. Interroga-se, notadamente, a posição do historiador na 'teia' que envolve o movimento da história e a construção da memória, atentando-se para as mediações entre acontecimentos, 
sua narração e suas posteriores interpretações (Vesentini, 1997; Pires, 1999). Que postura e importância ocupam os museus de história diante desses posicionamentos? Por quais caminhos se entrelaçam o tempo presente e lugares deliberadamente destinados a fazer chegar até nós a glorificação do passado nacional?

\section{VER, FAZER VER E REFAZER SIGNIFICAÇÕES}

Eu me lembro ainda da emoção, sempre a mesma e sempre viva, que fez disparar meu coração, quando, pequeno, entrei sob as abóbadas sombrias e contemplei as fisionomias pálidas, quando ia e procurava, ardente, curioso, medroso, de sala em sala, de época em época ... Eu buscava o quê? Não sei: a vida de então, sem dúvida, $e$ o gênio do tempo.

Michelet, citado por Georgel, 2005, p.120

Ao abordar as profundas articulações entre a instituição museu e a produção da escrita da história, durante o século XIX, Chantal Georgel recorreu a anotações de Michelet, na História da Revolução Francesa, editada entre 1847 e 1853, recordando a visita que realizou, quando criança, ao Museu de Monumentos Franceses, criado por Lenoir, nos fins do século XVIII. ${ }^{12}$

Para Georgel, as palavras de Michelet registram como a história se configurou para ele a partir dessa experiência. Sublinham, igualmente, a maneira pela qual se considerava que em um museu, por meio do apelo visual a imagens, ruínas e objetos, a história seria não só ensinada como teria a capacidade de ressuscitar. Nesse direcionamento, podem ser também interpretadas as observações de José Veríssimo, feitas nos fins do século XIX, quando aliou museu e história pátria.

Porque não é somente nas escolas ou pelo estudo de autores e documentos que se pode estudar a história pátria ... Os monumentos, os museus, as coleções arqueológicas e históricas, essas construções que nossos antepassados com tanta propriedade chamaram memórias, são outras tantas maneiras de recordação do passado, do ensino histórico e nacional... (Veríssimo, 1985) 
Em vários de seus trabalhos, ${ }^{13}$ Manoel Luiz Salgado Guimarães se preocupou com os vínculos entre museus de história e formas de visualização do passado, tomando como ponto de partida as relações entre o visível e o invisível, que estão "na raiz mesma do trabalho do historiador", conforme observou. Para discorrer sobre o tema, mencionou, entre outras referências, duas citações - extraídas de um romance de Madame de Staël e de uma carta de Freud - que foram formuladas, respectivamente, no início do século XIX e no início do século $\mathrm{XX}$, mas que julgo pertinente retomar, pois desdobram o registro de Michelet.

Na obra Corinne ou l'Italie, escrita por Madame de Staël e publicada pela primeira vez em 1807, a protagonista em dado momento da visita à cidade de Roma observa:

É em vão que se confia na leitura da história para compreender o espírito dos povos; aquilo que se vê excita em nós muito mais ideias que aquilo que se lê, e os objetos exteriores provocam uma emoção forte, que confere ao estudo do passado o interesse e a vida que se encontram na observação dos homens e dos fatos contemporâneos... (Guimarães, 2007)

No romance, é a visão das ruínas da antiga Roma, mais do que a leitura de textos eruditos, que sustenta o entendimento dos nexos entre passado, presente e futuro, bem como o saber sobre a história. Cabe lembrar, nesse sentido, palavras de Hartog segundo as quais no regime de historicidade moderno há uma nítida quebra entre passado e presente; a história passa a ser compreendida enquanto processo único, como narrativa do unívoco. Além disso, os acontecimentos ocorrem pelo tempo e faz-se premente e necessário visitar o passado para antever o futuro (Hartog, 2013, p.77-162).

Mas a essa experiência de conhecimento poder-se-ia acrescentar outra, também proporcionada pela observação de sítios erguidos e habitados na Antiguidade. Encontra-se em um texto de Freud, que descreveu em 1936 a lembrança de uma situação vivenciada em 1904, quando realizou viagem de férias a Atenas. ${ }^{14} \mathrm{O}$ contato direto com a Acrópole e as ruínas gregas era um sonho de há muito alimentado por ele e uma das sensações provocadas por esse cenário foi a de que "existia mesmo tudo aquilo, da maneira como aprendêramos na escola", do modo como os livros ensinavam e ajudavam a imaginar. Se para a personagem Corinne a fruição imediata e visível do passado 
inaugura o caminho para a imaginação e para o conhecimento, revelando-se muito mais preciosa que qualquer livro, para Freud é a percepção sensorial das ruínas de Atenas que veio comprovar o que os livros continham, legitimando o saber conservado em suas páginas.

As duas situações não se contradizem, ao contrário, se completam, apontando por vias singulares as relações entre visão, escrita e conhecimento do mundo, assim como - e sobretudo - a importância atribuída ao olhar como mediação para o saber e para as impressões indeléveis que deveria provocar no ser humano. A crença nessa relação, intermediada pela ação do historiador, emerge nas cartas que Affonso Taunay trocou com alguns dos intelectuais de sua época, entre os quais Teodoro Sampaio e particularmente Roquette Pinto.

Para que a influência pedagógica e civilizadora do Museu Paulista pudesse ser exercida de maneira eficaz, Roquette Pinto, em 1918, respondendo consulta de Taunay sobre os elementos que deveriam compor a ornamentação interna do edifício do Museu, destinada à comemoração do centenário da Independência, observou:

Em geral, o nosso povo se esquece de seus grandes homens porque os documentos de seu viver, suas relíquias, tudo quanto guarda o reflexo de sua vida ou é destruído e disperso ou é recluso a sete chaves. O povo aceita a existência de Martim Afonso, atento ao que disseram na escola: vendo agora as linhas que a mão venerável do donatário traçou, para entregar um pedaço de terra brasileira a um de seus primeiros povoadores, o povo ingênuo acabará firmemente convencido da realidade de sua existência... ${ }^{15}$

São conhecidas as expressões de Paul Valéry que procurou definir os museus como locais destinados à reunião de coisas raras e belas que "instruíam o olho a olhar" (Samaran, 1961, p.1024). Esses espaços ensejavam oportunidade para o conhecimento e a incorporação - pela visão e pela emoção - dos critérios, valores e hierarquias da ciência e da estética, tesouro cultural a ser admirado e preservado. Na mesma década de 1920, porém, Valéry também elaborou longa digressão sobre o mal-estar que uma visita a um museu poderia provocar. Não questionava os procedimentos classificatórios e de conservação, tampouco sua utilidade pública. Constrangeram-no os gestos autoritários de não poder falar normalmente e de portar-se como se estivesse num santuário, ao mesmo tempo em que, diante das maneiras pelas quais esculturas e pinturas 
estavam expostas, sentiu-se envolvido por "fria confusão" e por "desordem organizada":

Eu não sabia mais o que estava fazendo nessas solidões enceradas, contidas no templo, no salão, no cemitério e na escola ... Estava me instruindo, ou buscando meu encantamento, ou cumprindo um dever e satisfazendo convenções? ... Como o sentido da visão se encontra violentado por este abuso de espaço que constitui uma coleção, também a inteligência está ofendida pela extensa reunião de obras importantes ... [Mas] o magnífico caos dos museus me seguiu e se combinou com o movimento vivo da rua... (Valéry, 1993, p.123, tradução nossa)

Dirigia sua indignação contra a forma de exposição que, ao invés de mobilizar sensações prazerosas e ativar os sentidos, especialmente o olhar, bloqueava observações e reflexões, em virtude da profusão de obras de arte reunidas em um único espaço. Parecia buscar, também, uma vinculação mais forte entre aquelas expressões de cultura e a vida cotidiana, sugerindo que normas rígidas de conduta e visitação poderiam impor distanciamento artificial entre esses espaços e a sociedade.

Durante a primeira metade do século XX aos museus, notadamente os de história, estavam destinadas funções aparentemente bem definidas, apesar de os debates sobre o tema reavivados com a criação do ICOM (International Council of Museums) em 1946 terem promovido contínua reformulação e alteração no modo de se entender as competências de um museu e suas áreas de intervenção. ${ }^{16}$ No entanto, como divulgado na conhecida obra L'Histoire et ses méthodes, nessas instituições o historiador poderia encontrar "provas autênticas das atividades do homem em todas as épocas e domínios". Eram "lugares de prazer" para os que se dispunham a acompanhar "a evolução social e as modificações dos modos de vida" ao longo do tempo e desempenhavam papel educativo junto à sociedade em geral, exercendo, ao mesmo tempo, atuação científica, pois se colocavam a serviço do saber, da preservação dos testemunhos da criação humana e de sua difusão (Samaran, 1961, p.1024ss).

Essas mesmas atribuições, mas agigantadas, foram o foco da atenção do então diretor do Museu Paulista, Mário Neme. Em 1962, no contexto de debates nacionais e internacionais em torno do papel democratizador da cultura que os museus poderiam assumir, ${ }^{17}$ Neme estava diretamente empenhado, em conjunto com outros professores e intelectuais, a exemplo de Sérgio Buarque 
de Holanda e Eurípedes Simões de Paula, para que a Universidade de São Paulo incorporasse definitivamente o Museu entre suas unidades. ${ }^{18}$

A proposta assentava-se no reconhecimento de que a Secretaria de Educação do Estado de São Paulo não tinha condições políticas e financeiras para, ao mesmo tempo, manter a rede de escolas públicas e sustentar uma instituição de tanta importância e potencialidade como o Museu Paulista. As carências financeiras e estruturais de que padecia o Museu, tratadas à exaustão por Sérgio Buarque de Holanda e Herbert Baldus em relatórios institucionais nas décadas de 1940 e 1950, ${ }^{19}$ só vinham consolidar, para Neme, questões de natureza conceitual debatidas naquela quadra, em particular a compreensão de que os museus deviam estar a serviço da sociedade e de seu desenvolvimento. Considerava que "o museu deve ser, principalmente, um instituto de pesquisa", voltado para a "utilização cultural e científica" de suas coleções, com forte presença na produção de conhecimentos históricos, no ensino universitário e na formação de recursos humanos especializados, o que tornava inescapável, para ele, sua transformação em autarquia, vinculada à Universidade e subvencionada pelo poder público. Por um lado, tratava-se de iniciativa que, sem dúvida, promovia outra ruptura na trajetória da instituição e demandava ampla reorganização interna, comparando-se talvez aos ajustes que marcaram a gestão Taunay, entre as décadas de 1920 e 1940. Por outro, a ênfase dada ao ensino superior e a relevância dessa opção para a conservação, ordenamento, estudo e exposição das coleções que o Museu havia acumulado, não implicavam, para o então diretor, descurar da atuação social e educativa que, a seu ver, era intrínseca aos museus, atualizando-se, porém, os nexos entre os sentidos, a emoção e o conhecimento.

Um museu - seja qual for o seu caráter, seja qual for o seu ramo, tem que se distinguir por duas capacidades essenciais com relação aos seus visitantes: a capacidade de impor respeito e a capacidade de despertar a emoção ... Há uma relação de causa e efeito, de ordem psicológica, que é cumprida e tem a sua consequência lógica no momento da visita ... A pessoa que se dispõe a visitar um Museu de História está psicologicamente preparada - com a "vontade de crer" - para encontrar nele ambiente e representações que lhe falem dos fatos históricos, das tradições maiores, dos feitos gloriosos, dos grandes homens da nacionalidade. $\mathrm{E}$ isto se aplica tanto ao homem do povo quanto ao escolar ... Pode falar-se neste caso da função cultural do museu em benefício de toda a comunidade. Mas, esta 
função somente se exerce com a eficácia desejada, com real proveito para o povo, se o material do museu ... consegue corresponder à "vontade de ver", à "inclinação de aprender"... (Neme, 1964, p.21, 44-45)

As ponderações de Neme - assim como já havia ocorrido com os registros de Ihering, primeiro diretor do Museu, e depois com Taunay - manifestavam não só um projeto político e de ação imediata, pois foi por intermédio do presente que ocorreu a recuperação do percurso histórico do Museu, atribuindo-se significação ao passado, ao tempo e às atitudes frente ao peso dessas instituições nos campos da cultura, da educação popular e na formação de pesquisadores e bacharéis. A despeito de suas palavras na defesa do Museu emergirem como a recriação de argumentos lançados em fins do século XIX ou nos inícios do século XX, entre esses momentos não há continuidades do ponto de vista conceitual no tocante ao Museu e à história que ele poderia narrar. O que houve foram rupturas - que ainda estão a merecer estudos detalhados - engendradas, como mencionei no começo deste artigo, no âmbito dos confrontos entre forças políticas, entre interlocutores que competiam e dividiam espaços, recursos financeiros e poderes, simultaneamente, na política e na produção do saber e da cultura. E isso em momento muito específico da vida nacional como foi o golpe de 1964 e a configuração da ditadura militar.

Só muito recentemente vêm sendo questionados, no âmbito dos museus, ${ }^{20}$ as relações entre visão e conhecimento, o caráter da educação e da formação cultural que podem oferecer e, notadamente, as relações que desde a origem mantêm com o tempo, o tempo presente, pois é por seu intermédio que o museu e suas significações se atualizam.

Tanto Nora quanto Hartog discutiram em seus escritos (Nora, 1984; Hartog, 2013, cap. IV) algumas das circunstâncias contemporâneas que têm contribuído para esgarçar e fragmentar os elos da sociedade com tradições e monumentos comemorativos da história nacional, realçando, em especial, duas delas: a clivagem entre a história ensinada nas instituições destinadas à educação e à cultura e as expectativas de crianças e jovens motivados pelas experiências de aceleração do tempo que a cultura virtual pode proporcionar; e os questionamentos acadêmicos em torno da maneira pela qual as histórias nacionais foram narradas quer por meio de registros escritos quer, 
particularmente, por meio de recursos visuais, a exemplo de obras de arte e objetos reunidos e expostos em museus.

Quanto a esse ponto é importante lembrar, também, observações de Dominique Poulot, para quem na atualidade e contrariamente às aparências "os trabalhos de confirmação entre museus de história e historiografia ou ensino da história são bastante fracos":

O museu de história trabalha com o repertório das fontes do historiador, sanciona a emergência de novas curiosidades, tem seu próprio peso nas vicissitudes dos interesses sábios, enquanto vulgariza mais ou menos bem os conhecimentos eruditos junto aos visitantes ... Passa por momentos de maior intensidade ou de fervor, quando o sentimento nacional o exige ... No entanto, o museu situa-se à margem da escrita da história, ao lado da compilação e da preservação de indícios do passado. Isolado da invenção intelectual dos escritos e dos reescritos, o museu também não constituiu uma matriz cultural, como a escola ... O espetáculo do museu ilustra ... a discrepância entre a escrita da história e uma representação do passado capaz de evocar, de outro modo que o da memória, o reconhecimento do passado como tendo sido, embora já não mais seja... (Poulot, 2003, p.43-44)

Uma avaliação preliminar nos números de visitantes fornecidos pelos relatórios institucionais do Museu Paulista, na segunda metade do século XX e início do século XXI, sugere que os argumentos de Poulot podem contribuir para a problematização dos modos pelos quais a instituição se inscreve na sociedade paulista e brasileira atualmente. Nos registros feitos entre 1947 e 1950, o então diretor Sérgio Buarque de Holanda frisava ao secretário de Educação que a visitação às dependências do Museu havia ultrapassado um milhão e duzentas mil pessoas. Por essa época, o Museu Paulista estava aberto ao público três dias na semana (terças-feiras, quintas-feiras e domingos) e não havia cobrança de ingresso. Eram cifras consideráveis, levando-se em conta que a cidade de São Paulo naquela época reunia mais de três milhões e meio de habitantes ${ }^{21}$ e que o Museu, tal como ainda hoje, era visitado por pessoas de todas as regiões do país e também do exterior.

Nos anos 1970, os números de visitantes mantiveram-se nos mesmos níveis, pois entre 1973 e 1976 frequentaram as exposições e demais atividades culturais do Museu perto de um milhão e cem mil pessoas, ressaltando-se que, a partir de 1973, houve a implantação de sistema de cobrança de ingressos. 
Mais tarde, entre 1999 e 2002, o público manteve-se na casa de um milhão, retornando ao patamar de um milhão e trezentas mil pessoas entre 2008 e $2012 .^{22}$

Esses dados sugerem uma retração da afluência de público e, aparentemente, uma diminuição da capacidade do Museu em oferecer propostas, atividades e exposições que viessem a ampliar cada vez mais o contingente de frequentadores. Tem-se a impressão de que a incorporação à Universidade, contraditoriamente, garantiu a sobrevivência do Museu e proporcionou condições para seu redirecionamento intelectual, mas, em contrapartida, houve um afastamento em relação à sociedade. No entanto, seria leviano neste estágio da pesquisa fazer qualquer suposição acerca das motivações para um possível refluxo da influência da instituição, ainda que as ponderações feitas por Poulot possam servir de horizonte de reflexão. Pesquisa recente entre crianças de escolas do município de São Paulo, e voltada para a compreensão das possíveis concepções que esse segmento de público poderia manifestar sobre esse gênero de instituição, revelou que mais de $43 \%$ dos entrevistados associavam 'museu' a Museu Paulista, evidenciando a profunda e tradicional vinculação, no imaginário coletivo, entre o edifício-monumento, a história e o espaço urbano paulistano (Selli, 2012-2013).

\section{“Lugar DE MEMÓRIA": O MUSEU E SEUS DESAFIOS}

Como explicar esta 'museofolia' que tomou conta da França e da maior parte dos países ocidentais? ... O sucesso desses lugares de peregrinação está na medida de uma memória desorientada: a nossa. Como reter o fio do tempo quando apenas duas gerações coabitam o mesmo teto, quando os objetos de nossa vida cotidiana se tornam obsoletos tão depressa...?

Emmanuel de Roux, 1988

Numa primeira aproximação, seria possível considerar o Museu Paulista como "lugar de memória" (Nora, 1984) e também de peregrinação, em virtude das injunções do edifício e de parcela de suas coleções com o delineamento da memória nacional. "Lugar de memória", expressão que se tornou tão banalizada entre nós, foi noção criada por Pierre Nora, na década de 1980, em meio 
ao debate que cercou o bicentenário da Revolução Francesa, e encontra-se ligada à reflexão sobre a configuração da França enquanto nação e remete aos modos pelos quais poder-se-ia escrever uma história nacional na década de 1980, momento daquelas comemorações.

Ao utilizá-la procuro, entretanto, seguir críticas feitas por François Hartog em relação aos possíveis usos dessa expressão que, ao invés de ser compreendida como sinônimo de museus, monumentos e construções historiográficas que sustentaram a história nacional no século XIX, oferece possibilidades para problematizar, sobretudo, procedimentos e representações que ajudaram a configurar a memória da nação e as tradições pelas quais chegou até nós. Hartog apontou vínculos entre o conceito, a obra Les Lieux de Mémoires e aquilo que denominou 'presentismo', uma relação específica com o tempo e o passado. O 'presentismo' seria um regime de historicidade ${ }^{23}$ assinalado por uma "progressiva invasão do horizonte por um presente mais e mais ampliado [e] hipertrofiado", o que teria se tornado visível a partir das décadas de 1970 e 1980. Para o historiador, "a força motriz foi o crescimento rápido e as exigências sempre maiores de uma sociedade de consumo, em que as descobertas científicas, as inovações técnicas e a busca de ganhos tornam as coisas e os homens cada vez mais obsoletos. A mídia, cujo extraordinário desenvolvimento acompanhou esse movimento que é sua razão de ser, deriva disso também: produzindo, consumindo e reciclando cada vez mais rapidamente mais palavras e imagens" (Hartog, 1996). Essas circunstâncias se expressariam, também, por intermédio da valorização da memória (voluntária, provocada, reconstruída), do patrimônio e das comemorações. Nesse sentido, conforme Hartog, a noção "lugar de memória" não poderia ser apreendida apenas de forma literal, mostrando-se mais como instrumento de investigação e interpretação que remete a preocupações específicas de como escrever uma história nacional na atualidade.

Penso, entretanto, que em razão disso mesmo é que se torna pertinente sua relação com o Museu Paulista. A expressão refere-se a lugares de natureza material, funcional e simbólica nos quais o presente e as demandas decorrentes da fluidez do tempo buscam suportes de recuperação do passado. Designa manifestações da tradição nacional, feixes de representações e redutos da história-memória autenticada pela política e por produções historiográficas do século XIX e também do século XX. O lugar não é simplesmente dado, como 
observa Hartog; é construído e reconstruído sem cessar, podendo ser interpretado como encruzilhada onde se encontram ou deságuam diferentes caminhos de memória.

Em concomitância às mediações entre história e memória, algumas reflexões de Paul Ricoeur e Fernando Catroga (1999, p.9-37) sugerem que museus podem ser vistos como locais para articulações entre memória e imaginação. Ambas evocam um 'objeto ausente' (ou uma presença ausente). Mas se o 'objeto ausente' pode ser ficcional para a imaginação, para a memória ele já não existe enquanto matéria embora tenha existido anteriormente. No caso dos museus de história nacional, e especialmente no percurso do Museu Paulista, esse aspecto adquire relevância, pois pinturas, esculturas, imagens e objetos reescrevem a história, evocam acontecimentos e personagens, representando o passado e ensejando sua 'visualização', como observou Stefan Bann (1994, p.153-180). Ou seja, tornam-se espaços de e para a imaginação do diversificado público que o frequenta e que necessariamente não compartilha as mesmas preocupações dos historiadores, tampouco observa o museu pela mediação do lugar social, da prática investigativa e da escrita que caracterizam, como sustenta Michel de Certeau (2006, p.65-106), a operação historiográfica.

Portanto, não se trata tão somente de indicar que o Museu abriga um imaginário no sentido mais literal do termo, como conjunto de imagens visíveis e simbólicas. Trata-se de refletir sobre a complexidade de um ambiente que, ao mesmo tempo, mediatiza e confere tangibilidade ao universo contraditório e multifacetado de representações por meio das quais os sujeitos históricos constroem sua vida no presente, estabelecem relações com o tempo, projetam interpretações sobre seu próprio percurso, sobre a trajetória da sociedade à qual pertencem e sobre os elementos materiais e simbólicos que a compõem, constituindo o que se convencionou denominar patrimônio cultural coletivamente compartilhado.

Talvez uma das razões do fascínio e do interesse que o Museu Paulista ainda desperta esteja no fato de reunir objetos e emblemas que permitem imaginar tanto a vida e costumes de tempos pretéritos como o cotidiano de personagens da história. Mas, ao contrário dos meios eletrônicos e virtuais, o Museu oferece algo que não pode ser desconsiderado: a experiência da releitura, o que abre a possibilidade da recriação e atualização da memória nacional. Como observou Ecléa Bosi: "lembrar não é reviver, mas refazer, reconstruir, repensar, 
com imagens e ideias de hoje, as experiências do passado ... a memória não é sonho, é trabalho..." (Bosi, 1994, p.53-63). Nesse sentido, cada visita ao Museu sugere uma experiência peculiar promovida pelas circunstâncias do momento, o que pode provocar percepções diversas sobre a própria instituição e sobre o que ela reserva, assim como outras inferências sobre o tempo e as relações entre presente e passado.

No momento em que se completam 50 anos de integração à Universidade de São Paulo - quando nova reorganização interna e, portanto, novas rupturas foram desencadeadas pela formalização da autonomia acadêmica, em 2010 - é preciso reconhecer que a instituição enfrenta limites físicos pela necessidade de reformas e ampliações adequadas ao crescimento dos acervos, e de recursos humanos, em razão do papel formador que exerce no âmbito da graduação, da pós-graduação e da preparação de profissionais nos campos da história e da museologia.

Talvez o maior desafio esteja, no entanto, na harmonização entre ser museu e, ao mesmo tempo, parte constitutiva de uma das mais importantes universidades brasileiras. Ser lugar de memória e ser lugar para a discussão dos fundamentos das narrativas sobre a história. Como encaminhar questões tão densas? Uma das possibilidades encontra inspiração em interrogações formuladas por Francisco Murari Pires quando, ao refletir sobre os liames entre historiadores antigos e modernos na produção atual da escrita da história, entrelaçou criticamente o peso do passado ao trabalho historiográfico no presente (Pires, s.d., p.14). Que autoridade herdamos daqueles que muito antes de nós se debruçaram sobre o tempo e suas significações? Práticas de conhecimento e modos de interpretação das fontes, enraizados no trabalho do historiador, poderiam ser considerados um 'fardo' a ser desfiado? Ou, sob o crivo da crítica, tanto procedimentos historiográficos herdados quanto museus consagrados seriam para nós um 'fio', a referenciar-nos como sujeitos 'neste nosso lugar e tempo'?

\section{REFERENNCIAS}

ARAUJO, Marcelo Mattos; BRUNO, Maria Cristina Oliveira (Org.) Memória do pensamento museológico contemporâneo: documentos e depoimentos. 2.ed. São Paulo: Pinacoteca do Estado de São Paulo; Icom, 2010. 
ARENDT, Hanna. Entre o passado e o futuro. São Paulo: Perspectiva, 1972.

BANN, Stephen. As invenções da história. São Paulo: Ed. Unesp, 1994.

BITTENCOURT, Vera Lúcia Nagib. Revista do Museu Paulista e(m) capas: identidade e representação institucional em texto e imagem. Anais do Museu Paulista, São Paulo: Museu Paulista da USP, v.20, n.2, p.149-184, jul.-dez. 2012.

BLOCH, Marc. Apologia da história. Rio de Janeiro: Zahar, 2001.

BOSI, Alfredo. Fenomenologia do olhar. In: NOVAES, Adauto (Org.). O olhar. São Paulo: Companhia das Letras, 1988. p.65-88.

BOSI, Ecléa. Memória e Sociedade: lembranças de velhos. 3.ed. São Paulo: Companhia das Letras, 1994.

BRANDÃO, Carlos Alberto Ferreira; COSTA, Cleide. Uma crônica da integração dos museus estatutários à USP. Anais do Museu Paulista, v.15, n.1, jan.-jun. 2007.

CATROGA, Fernando. O céu da memória. Coimbra: Minerva, 1999.

CERTEAU, Michel de. A escrita da história. 2.ed. Trad. M. L. Menezes. Rio de Janeiro: Forense Universitária, 2006.

CHOAY, Françoise. A alegoria do patrimônio. São Paulo: Estação Liberdade; Ed. Unesp, 2001.

DE ROUX, Emmanuel. In: Le Monde, 14 Jan. 1988. In: SCHAER, Roland. L'invention des musées. Paris: Gallimard, 1993. p.132.

DOSSIÊ Museus da USP. Estudos Avançados, v.25, n.73, 2011.

FARGE, Arlette. Lugares para a história. Belo Horizonte: Autêntica, 2011.

FEBVRE, Lucien. Combats pour l'histoire. Paris: Armand Colin, 1965.

GAGNEBIN, Jeanne Marie. Sete aulas sobre linguagem, memória e história. Rio de Janeiro: Imago, 2005.

GEORGEL, Chantal. L'histoire au musée. In: AMALVI, Christian (Dir.). Les lieux d'Histoire. Paris: Armand Colin, 2005. p.118-126.

GUIMARÃES, Manoel Luiz Salgado. Expondo a história: imagens construindo o passado. In: .; RAMOS, Francisco Régis Lopes (Org.) Futuro do pretérito: escrita da história e história dos museus. Fortaleza: Instituto Frei Tito de Alencar, 2010. p.34-49.

. Expondo o passado: imagens construindo o passado. Anais do Museu Histórico Nacional, Rio de Janeiro: Minc/Iphan, v.34, p.71-86, 2002.

. Vendo o passado: representação e escrita da história. Anais do Museu Paulista, São Paulo: Museu Paulista da USP, v.15, n.2, jul.-dez. 2007, p.11-30.

HARTOG, François. Evidência da história. Belo Horizonte: Autêntica, 2011.

. Le miroir d'Hérodote. Paris: Gallimard, 2001. 
HARTOG, François. Patrimônio e presente. In: Regimes de Historicidade. Trad. Meneses, Beffart et al. Belo Horizonte: Autêntica, 2013.

. Tempo e história: como escrever a história da França hoje? História Social, Campinas (SP): Unicamp/Programa de Pós-Graduação em História, n.3, p.127154, 1996.

.; REVEL, Jacques. Les usages politiques du passé. Paris: Ehess, 2001.

KOSELLECK, Reinhart. Futuro passado. Rio de Janeiro: Contraponto; Ed. PUC, 2006.

L'ENCYCLOPÉDIE ou Dictionnaire raisonée des sciences, des arts et des métiers, dirigée par Diderot et D'Alembert, 1751/1772. v.10, p.893-894. Disponível no portal Enciclopédie en line; Acesso em: 3 jul. 2013.

LARA FILHO, Durval. Museu: de espelho do mundo a espaço relacional. Dissertação (Mestrado) -Escola de Comunicações e Artes, USP. São Paulo, 2006.

LORIGA, Sabina. O pequeno X: da biografia à história. Belo Horizonte: Autêntica, 2011.

MAKINO, Miyoko. Cronologia do Museu Paulista/USP. Suplemento Especial do Diário Oficial do Estado de São Paulo, São Paulo, v.107, n.220, 15 nov. 1997.

MENESES, Ulpiano Toledo Bezerra de. Do teatro da memória ao laboratório da História: a exposição museológica e o conhecimento histórico. Anais do Museu Paulista, São Paulo: Museu Paulista da USP, v.2, p.9-42, jan.-dez. 1994.

. O museu e a questão do conhecimento. In: GUIMARÃES; RAMOS (Org.), 2010, p.13-33.

NEME, Mário. Utilização cultural de material de Museu. Anais do Museu Paulista, São Paulo: Niamar, Tomo XVIII, p.7-62, 1964.

NORA, Pierre. Apresentação. In: . (Dir.). Les lieuxs de mémoires. Paris: Gallimard, 1984. v.1, p.VII-XLII;

OLIVEIRA, Cecilia Helena de Salles. Entre história e memória: a visualização do passado em espaços museológicos. Anais do Museu Paulista, São Paulo: Museu Paulista da USP, v.15, n.2, p.37-43, 2007.

O espetáculo do Ypiranga: mediações entre história e memória. Tese (Livre Docência) - Museu Paulista da USP. São Paulo, 1999. 2012.

Relatório de Gestão, 2008/2012. São Paulo: Diretoria do Museu Paulista, dez.

PIRES, Francisco Murari. Mithistória. São Paulo: Humanitas, 1999.

. O fardo e o fio. s.d. Disponível em: www.fflch.usp.br/dh/heros/fardo; Acesso em: 7 maio 2013.

(Org.). Antigos e modernos: diálogos sobre a (escrita da) história. São Paulo: Alameda, 2009. 
POULOT, Dominique. Nação, museu, acervo. In: TOSTES, Vera; BITTENCOURT, José Neves; BENCHETRIT, Sarah (Org.). História representada: o dilema dos museus. Rio de Janeiro: Museu Histórico Nacional, 2003. p.43-44.

PRAËT, Michel Van. Les musées d'histoire naturelle: savoirs, patrimoines et profissionalisation. In: BOUDIA, Soraya; RASMUSSEN, Anne; SOUBIRAN, Sébastien (Dir.). Patrimoine et Communautés savantes. Rennes: Presses Universitaire de Rennes, 2009. p.125.

REVEL, Jacques. Proposições: ensaios de história e historiografia. Rio de Janeiro: Ed. Uerj, 2009.

SAMARAN, Charles (Dir.). L'Histoire et ses méthodes. Paris: Gallimard, 1961.

SARLO, Beatriz. Tempo passado: cultura da memória e guinada subjetiva. São Paulo: Companhia das Letras; Ed. UFMG, 2007.

SELLI, Paula H. O Museu Paulista e as concepções de museu. Revista do Centro de Patrimônio Cultural da USP, São Paulo: CPC/USP, n.15, p.67-84, nov. 2012-abr. 2013. Disponível em: www.usp.br/cpc.

VALÉRY, Paul. Le problème des musées. Pièces sur l'art, 1923. In: SCHAER, Roland. L'invention des musées. Paris: Gallimard, 1993.

VERÍSSIMO, José. Educação Nacional. 3.ed. Porto Alegre: Mercado Aberto, 1985.

VESENTINI, Carlos Alberto. A teia do fato. São Paulo: Hucitec; PPG História Social, 1997.

\section{NOTAS}

${ }^{1}$ Este artigo faz parte de pesquisa mais ampla, em andamento, financiada pela Pró-Reitoria de Cultura e Extensão da USP, destinada à produção de documentário sobre os 50 anos de incorporação do Museu Paulista à Universidade de São Paulo. Além disso, fundamenta-se, também, na experiência de trabalhar há mais de 20 anos nessa instituição e de ter tido a honra de ser eleita para dirigi-la, entre fevereiro de 2008 e fevereiro de 2012.

${ }^{2}$ GUIMARÃES, 2007. Ver, também, no mesmo volume dos Anais do Museu Paulista, os vários comentários ao artigo de Guimarães.

${ }^{3}$ Ibidem. Consultar, também, GUIMARÃES, 2010.

${ }^{4}$ PRAËT, 2009, p.125. Sobre as vinculações entre museus de história, conflitos de poder e política, consultar BITTENCOURT, 2012.

${ }^{5}$ Sobre o tema, consultar: HARTOG; REVEL, 2001.

${ }^{6}$ Sobre a configuração da noção de patrimônio e suas repercussões na sociedade moderna e contemporânea, consultar, entre outros, CHOAY, 2001; a coletânea Patrimoine et Communautés savantes e o capítulo "Patrimônio e presente" em HARTOG, 2013, p.193ss. 
${ }^{7}$ Ver, especialmente, OLIVEIRA, 2007, p.37-43, e OLIVEIRA, 1999, primeira parte.

${ }^{8}$ Entende-se por curadoria o conjunto de atividades organicamente desenvolvidas em torno de acervos conservados em museus. São elas: formação de coleções, estudo e documentação de coleções; preservação e organização física de unidades e coleções em reservas técnicas; bem como difusão de acervos e de conhecimentos produzidos por intermédio de seu estudo e problematização, o que pode se dar através das práticas de divulgação científica tradicionais (como conferências, reuniões científicas, elaboração de livros, artigos, comunicações em eventos etc.) e, também, por meio de exposições, mostras e materiais didáticos para uso do público em geral ou de professores e educandos de ensino fundamental e médio. Sobre o tema, consultar especialmente os Relatórios institucionais do Museu Paulista, disponíveis no Serviço de Documentação Textual e Iconografia e as Resoluções n.5300 e 5301, aprovadas pelo Conselho Universitário da USP, em dezembro de 2012, disponíveis no portal www.usp.br/normas.

${ }^{9}$ GAGNEBIN, 2005, p.13-ss; PIRES, s.d. Ver, também, sobre o tema os trabalhos de HARTOG, especialmente 2011, cap. IV.

${ }^{10}$ Vera Lúcia Nagib Bittencourt (2012) discute de que modo, nas primeiras décadas de organização do Museu Paulista, a trajetória da instituição esteve atravessada por embates em torno do passado e de projetos de nação que envolviam o privilegiamento de determinados campos do saber, particularmente a história natural, e sua eficácia na definição de políticas públicas voltadas para a produção agrícola, a expansão territorial de São Paulo e a formação do cidadão, o que envolvia diretamente uma narrativa sobre a história. A passagem para a direção de Affonso Taunay representaria uma alteração política e de poder, ao mesmo tempo, um redirecionamento nos modos de produzir e divulgar a história.

${ }^{11}$ Refiro-me, particularmente, à recuperação das reflexões de Lucien Febvre e Marc Bloch e a estudos de vários outros autores que tem procurado discutir os fundamentos da história. Menciono para situar o debate: BLOCH, 2001; FARGE, 2011; REVEL, 2009; ARENDT, 1972; FEBVRE, 1965; HARTOG, 2001; LORIGA, 2011; KOSELLECK, 2006; PIRES, 2009.

${ }^{12}$ Sobre o tema, consultar: BANN, 1994.

${ }^{13}$ Ver, especialmente, GUIMARÃES, 2002.

${ }^{14}$ Foi Manoel Luiz Salgado Guimarães quem analisou e traduziu a experiência de Freud em GUIMARÃES, 2002, p.71-72.

${ }^{15}$ Relatório do Museu Paulista enviado a Rodrigues Alves por Affonso Taunay, em 1918. Serviço de Documentação do Museu Paulista da USP.

${ }^{16}$ Sobre o tema consultar, entre outros: MENESES, 1994; MENESES, 2010; ARAUJO; BRUNO (Org.), 2010.

${ }^{17}$ Sobre o assunto, consultar a obra de Araújo e Bruno já citada. Ver, também, LARA FILHO, 2006.

${ }^{18}$ NEME, 1964, Tomo XVIII, p.7-62. Nos limites desse artigo, não me proponho a analisar a densa perspectiva histórica e teórica desenvolvida por Neme sobre os museus, em geral, e 
sobre as condições específicas de transformação do Museu Paulista em unidade da USP, lembrando-se que, desde a criação da Universidade, em 1934, o Museu era considerado seu instituto complementar. Tanto a figura desse intelectual quanto as condições que nortearam a transferência do Museu da Secretaria de Educação para a USP, em 1963, ainda aguardam pesquisa de fôlego. Circunscrevo-me a indicar de que modo, naquele momento, e no âmbito de debate sobre o futuro do Museu Paulista e da constituição de uma política oficial de museus para o país, Mário Neme definiu o escopo de atuação dessas instituições. Sobre a integração do Museu de Zoologia e do Museu de Arte Contemporânea à USP, bem como sobre a criação e reorganização do Museu de Arqueologia e Etnologia nos quadros da mesma universidade, consultar: BRANDÃO; COSTA, 2007; e DOSSIÊ MUSEUS DA USP, 2011.

${ }^{19}$ Ver: Relatórios institucionais do Museu Paulista, produzidos por Sérgio Buarque de Holanda e pelo diretor-substituto Herbert Baldus, 1950, 1951, 1952, 1953, 1954, 1955, 1956, 1957 e 1958. Serviço de Documentação Textual e Iconografia do Museu Paulista da USP. Consultar, também, MAKINO, 1997. Agradeço ao aluno do Curso de Graduação em História da FFLCH/USP Heitor Reider Rodrigues Bohn o auxílio para a coleta de dados junto aos relatórios institucionais.

${ }^{20}$ Ver sobre o tema os artigos já mencionados de Manoel Luiz Salgado Guimarães e Ulpiano Toledo Bezerra de Meneses.

${ }^{21}$ Os dados sobre a população da cidade de São Paulo, entre os fins do século XIX e os dias atuais, podem ser encontrados no sítio www.smdu.prefeiturasp.gov.br/histórico; Acesso em: 3 jul. 2013.

${ }^{22}$ Relatórios institucionais do Museu Paulista da USP, 1974 a 1979. Revista do Museu Paulista, tomos 21 (1974), 22 (1975), 23 (1976), 24 (1977), 25 (1978) e 26 (1979). Coleção disponível na Biblioteca do Museu Paulista. Dados coletados por Heitor Reider Rodrigues Bohn; Anuário Estatístico da USP, 1999/2002, disponível no portal da USP: www.usp.br/ anuário; OLIVEIRA, 2012.

${ }^{23} \mathrm{~A}$ expressão 'regime de historicidade' remete às reflexões desenvolvidas por François Hartog acerca do tempo e das diferentes maneiras pelas quais foi apropriado, compreendido e exercido no âmbito da escrita da história. Trata-se, simultaneamente, de instrumento heurístico e de categoria histórica de pensamento que permite interrogar, segundo o autor, os modos pelos quais, ao longo do tempo, configuraram-se articulações específicas entre passado, presente e futuro. Combatendo qualquer simplificação de ordem linear ou evolutiva, $o$ que Hartog investiga são os fundamentos da atual relação com o tempo, o que denominou 'presentismo', e seu entrelaçamento com a escrita da história. Ver: HARTOG, 2013, especialmente Prefácio e Introdução. Cabe lembrar que as reflexões de Hartog estão inscritas em amplo debate do qual fazem parte, entre outras, as contribuições essenciais de Lucien Febvre e Reinhart Koselleck, já citados. Sobre o tema, consultar também: CERTEAU, 2006.

Artigo recebido em setembro de 2013. Aprovado em outubro de 2013. 